\title{
Erdal Zengin
}

Mehmet Turan

Frrat University, Elazığ-Turkey

ezenginefirat.edu.tr; mturanefirat.edu.tr

\begin{tabular}{l|l|l|l}
\hline DOI & \multicolumn{3}{|c}{ http://dx.doi.org/10.12739/NWSA.2020.15.4.1C0701 } \\
\hline \multicolumn{2}{l|}{ ORCID ID } & $0000-0002-477-0160$ & $0000-0001-6963-4827$ \\
\hline \multicolumn{1}{l}{ CORRESPONDING AUTHOR } & Erdal Zengin \\
\hline
\end{tabular}

\section{İLKOKUL ÖĞRENCİLERININ ÇANTA VE BENZERI EŞYALARI KULLANMA DURUMUNA İLIŞKIN BIR ARAŞTIRMA}

Öz

Araştırma 2016 yılında Elazığ ilinde 5 ilkokulda öğrenim gören toplam 910 ilkokul öğrencisi üzerinde yürütülmüştür. Araştırma tarama modelinde olup, betimsel bir nitelik arz etmektedir. Araştırma sonucunda; öğrencilerin en az $106 \mathrm{~cm}$, en fazla $152 \mathrm{~cm}$ olmak üzere, ortalama boy uzunluğu $128.46 \mathrm{~cm}$ olarak tespit edilmiştir. Yine öğrencilerin en az $16 \mathrm{~kg}$, en fazla $65.60 \mathrm{~kg}$ olmak üzere, ortalama kilo durumu 28.48 olarak tespit edilmiştir. Yine öğrencilerin en az $1 \mathrm{~kg}$, en fazla $8.90 \mathrm{~kg}$ ve ortalama $3.56 \mathrm{~kg}$ ağırlığında çanta taşıdıkları tespit edilmiştir. Öğrenci kilo ve taşıdıkları çanta ağırlığı oranlaması sonucunda; öğrencilerin vücut kilosunun 이 oranında çanta ağırlığına sahip olduğu ve bu durumun bazı öğrencilerin fizyolojik gelişimleri açısından önemli sorunlar oluşturabileceği tespit edilmiştir. Ayrıca öğrencilerin çantasında ortalama 5.32 adet kitap ve ortalama 4.39 adet defter bulunduğu da tespit edilmiştir. Araştırma sonucunda öğrencilerin \%63.5'inin beslenme çantasına; \%87.8'inin suluk; \%99.2'sinin kalemlik ve ㅇ.4'ünün de resim çantasına sahip oldukları tespit edilmiştir.

Anahtar Kelimeler: İlkokul, Okul Çantası, Çanta Ağırlığı, Aidiyet, Ağırlık

\section{A RESEARCH ON THE USE OF BAGS AND SIMILAR ITEMS OF PRIMARY SCHOOI STUDENTS}

\section{ABSTRACT}

The research was conducted in 2016, on 910 students who were from 5 different primary schools in Elazığ. Research is in scanning model, it has a descriptive quality. As a result of the research; it was detected that, the average stature, the minimum was $106 \mathrm{~cm}$ and the maximum was $152 \mathrm{~cm}$, was $128.46 \mathrm{~cm}$. likewise, the average weight, the minimum was $16 \mathrm{~kg}$ and the maximum was $65.60 \mathrm{~kg}$, was detected as $28.48 \mathrm{~kg}$. Also, it was detected students were carrying schoolbags that had average of $3.56 \mathrm{~kg}$ while the minimum bag weight was $1 \mathrm{~kg}$ and the maximum was $8.90 \mathrm{~kg}$. After rating students' weights to weights of the bags they were carrying; it was detected that bag weights were 8\% of their self weight and this might cause some students have crucial problems in their physiological developments. Furthermore, after the research, it was detected that students had 5.32 books and 4.39 notebooks on average in their bags and 63.5\% of students had lunch boxes, 87.8\% had water bottles, 99.2\% had pencil cases and $2.4 \%$ had portfolios.

Keywords: Primary School, Schoolbag, Bag Weight, Belonging, Weight

How to Cite:

Zengin, E. ve Turan, M., (2020). İlkokul Öğrencilerinin Çanta ve Benzeri Eşyaları Kullanma Durumuna İlişkin Bir Araştırma, Education Sciences (NWSAES), 15(4):85-98, DOI: $10.12739 /$ NWSA.2020.15.4.1C0701. 
Zengin, E. ve Turan, M. , Education Sciences (NWSAES), 1C0701, 2020; 15(4):85-98.

\section{GIRISS (INTRODUCTION)}

6-12 yaşlar arasında, bireyler sahip oldukları fiziksel niteliklerle çoğu kez ilgili oldukları, ebeveynlerinden uzaklaşarak sosyal bir çevreye sahip olmak için adım attıkları, sosyal yaşamda vuku bulan olaylara ilginin daha fazla olduğu, arkadaşlık ilişkilerin geliştirilerek gerçek manada sosyalleşmenin olduğu dönemi ifade eder. Okula başlamanın başlangıcı olarak ifade edilen bu dönem, aynı şekilde bireyin sosyalleştiği ortamın köklü bir şekilde değişime uğradığı bir zamanı ifade eder (MEGEP). Aynı zamanda çocuğun okul hayatına başladığı dönemi de içinde barındırır. Bu dönem sonraki eğitim ve öğretim kademelerine temel teşkil etmekte [32]. i̇lköğretimin hedefi; her Türkiye vatandaşını iyi birer insan olması için, ihtiyacı olan ilk basamak bilgilerin, beceri, davranış ve alışkanıık kazanmasını, içine yaşadığı tolumun ahlaki kurallarına uygun bir şekilde eğitilmesini, ilgi, istidat ve yetenekleri açısından yaşama ve bir sonraki öğrenim düzeyine bir ön hazırlık oluşturmaktır [18]. Gündüz ve Özarslan (2016)'ın aktardığına göre yapılan çalışmalar bireyin eğitim-öğretime girişe hazır olması ile daha sonraları olacak olan okul başarısı arasında paralellik olması ve yaşamındaki yeterliliği arasında çok iyi derecede bir yakınıığın olduğunu göstermektedir. Bu yüzden eğitim-öğretime giriş kararı, ileriki yıllarla olan ilişkisinden dolayı bireyin yaşamında önemli bir yeri olan bir etkiye sahiptir. Küresel olarak çocukların eğitim-öğretime hazır olup olmamaları siyasetçiler, eğitimciler ve ebeveynler içine önemli bir karar aşaması olmuştur. Bu süreçte birey için önemli kriterlerden biri, okul eğitimi için ihtiyaç olan bütün eğitim alanlarında, yeteri oranda hazırlık seviyesine ulaşmalı. Araştırmacılar, eğitim kurumuna uyum çok çeşitli niteliklere sahip olduğu vurgulanmakta ve bireylerin sadece eğitim-öğretimdeki başarısı olarak değil, bununla birlikte bireylerin eğitim kurumlarına yönelik duygusal beceri ve davranışlarını ve eğitim kurumlarının ortamına müdahil olunan bir durum olarak da açıklanabilir.

Eğitim-öğretimin ortamı, toplumsal çevresi ile kişinin sağlık durumuna direk olarak etkilemektedir. Eğitim-öğretim ortamı, sağlıkla ilgili doğru bir perspektif ortaya koymasına veya sağlık uygulamalarından bir arada verilmesine yatkın bir konum teşkil etmesi sebebiyle, sağlık taramaları açısından çok önemli bir alanı teşkil etmektedir. Koruyucu sağlık uygulamaları altında eğitim-öğretim kurumlarında çok fazla tarama planları uygulamaya konulmaktadır. Bunların en önde geleni omurgayla ilgili olan sağlık taramalarıdır. Bireylerin eğitim-öğretime başlamasıyla gündemi teşkil eden hareketsiz hayat, sürekli hareketsiz kalma süreleri, bilgisayarların yaşamı kuşatması, ağırlıkları yüksek çantaların taşınması, dönemin beraberinde ortaya çıkardığı duruma şekil bozuklukları ve omurgayı ilgilendiren şekil bozukluklarını gündeme getirmektedir [4]. Okul öğrencileri genellikle okul çantası içinde ders kitaplarını, spor kıyafetlerini, paketlenmiş yemeklerini ve kırtasiye eşyalarını taşırlar. Dünyada bugünlerde çocukların okul çantaları içinde ağır yük taşıdığı ile ilgili giderek artan edişeler var. Bazı ülkelerde çocukları bu yükten kurtarma için öğrencilere dizüstü bilgisayar ve tablet temininde bulunmuş ve çocukların sürekli internete bağlı olmalarını sağlayarak taşıdıkları o ă̆ır kitap yükünden kurtarmaya çalışmışlardır [14].

Son birkaç yılda, öğretmenler, okul yöneticileri, ebeveynler ve sağlık uzmanları arasında, çocukların ve ergenlerin omurilik ve omuz sorunlarına okul sırt çantalarının etkisi üzerine artan bir endişe var. Çocukların ve ergenlerin sırt çantası yüklerinin vücut ağırlığının olo ile 15'ini geçmemesi gerektiğini ve çoğu da o15'ten az olması gerektiği konusunda görüşleri ağır basmaktadır. Örneğin, Amerikan Kayropraktik Birliği, Amerikan Fizik Terapi Birliği ve Amerikan Ortopedik Cerrahlar Akademisi tarafından çanta ağırlıklarının o15 olması önerilmektedir. Buna rağmen, her yaştaki öğrenciler sürekli bu oranın üstünde ağırlık 
taşımaktadırlar [6, 7, 8, 15, 20, 23, 25 ve 29]. Ağır yük taşımanın fiziksel rahatsızlık veya kas iskelet sistemi hastalıkları [MSD] ile ilişkilendirmek oldukça sezgisel olmasına rağmen bilimsel topluluk, yük boyutu ile MSD arasında net bir neden-sonuç ilişkisi olup olmadığını tartışmaktadır, çünkü okul çantası tasarımı, maruz kalma süresi, fiziksel olgunluk ve yaşam tarzı önemli bir rol oynayabilir. Üstelik, duruş ve denge, sırtın yükünün büyüklüğü ve konumu tarafından kesinlikle değişikliğe uğradığında bunlar gözlemlenebilir tek olumsuz etken değildir [3 ve 10]. Çağdaş toplumda kas-iskelet sistemi ağrıları önemli bir sorun oluşturmaktadır. Epidemiyolojik veriler, bel ağrısının sadece yetişkinler grubunda değil, aynı zamanda çocuklar ve gençler arasında yağın olduğunu söylemektedirler. Sırt ağrılarını etkileyebilecek potansiyel okul sırt çantası ağırlığı, okul mobilyaları ve psikososyal faktörler vardır. Sırt ağrısı sadece tıbbi bir sorun değil aynı zamanda sosyo-ekonomik problemdir. Bu problem öğrencilerin sınırlı bir şekilde çalışmasına neden olabilir, günlük yaşamda, çalışamama ve daha büyük sayıda hastalığa sebep olabilir [1, 5, 28 ve 30].

Devamlı olarak sırt çantası kullanımı, omurga üzerine yük taşıma, yakından ve simetrik olarak taşınması sorun olarak ortaya çıkmakta. Yetişkinler kadar işyeri standarları imkanlarına sahip olamayan öğrenciler kendi eğitimi için gerekli olan okul materyallerini taşımak zorundadırlar. Taşıdıkları sırt çantalarının baş ve gövdelerine olan etkileri günlük yaşamlarındaki stresi de tetiklemektedir. Okulda öğrencinin yaşadığı ağrılar ve eğitimine engel teşkil eden durumlar günlük hayatını da etkilediğini söyleyebiliriz [22, 26 ve 27]. Yapılan bu araştırmalardan da anlaşılacağı üzere ilkokul çağında çocukların aşırı ağırlıkıı çanta taşımaları, yaşamlarında fizyolojik ve psikolojik birçok negatif etki oluşturmaktadır. Dolayısıyla ilkokulda öğrenim gören öğrencilerin fiziksel özellikleri ile çanta içerik ve ağırlıklarının mevcut durumunun tespiti, öğretim sürecinin etkili ve verimli yürütülmesi açısından önemlidir.

\section{2. ÇALIŞMANIN ÖNEMİ (RESEARCH SIGNIFICANCE)}

Bu araştırma, ilkokulda öğrenim gören öğrencilerin bazı fiziki özellikleri ile çanta ve benzeri eşyaları kullanma sıklığına yönelik mevcut durumu belirlemeyi amaçlamaktadır. Bu amaç doğrultusunda; "İlkokul öğrencilerinin çanta ve benzeri eşyaları kullanma durumu nedir? İlkokul öğrencilerinin kendi yaş, boy ve kilo oranına göre taşıdıkları yük miktarı nedir?" sorularına cevap aranmışır. Bu araştırma ile öğrencilerin okula götürdükleri eşyaların boy ve kiloları ile orantılı olup olmadığı ortaya konması hedeflenmektedir. Böylece ilkokul öğrencilerinin taşıdıkları yük miktarının gelişim dönemleri ile orantılı olup olmadığı ortaya konacaktır. Ayrıca, literatürde böyle bir çalışmanın daha önce hiç yapılmamış olması alanyazının bu konudaki eksikliği, bu çalışma ile cevaplanacağı düşünülmektedir.

\section{YÖNTEM (METHOD)}

\subsection{Evren ve Örneklem (Universe and Sample)}

Bu araştırma, ilkokullarda öğrenim gören öğrencilerin fiziksel özellikleri ile çanta içerik ve ağırlıklarının mevcut durumunu belirlemeyi amaçlamaktadır. Araştırma, betimsel tarama modelindedir. Bunun için, araştırmacılar tarafından bir gözlem formu oluşturulmuştur. Araştırma 2016 yılında Elazığ ilinde 5 ilkokulda öğrenim gören toplam 910 ilkokul öğrencisi üzerinde yürütülmüştür. Bu öğrencilerin 810 tanesi Elazığ il merkezinde bulunan ilkokullarda, 5 tanesi Elazığ iline bağlı belde ve köylerde ve 50 tanesi ise Elazığ ilinde eğitim-öğretime devam etmekte olan özel okullarda eğitim alan öğrencilerden oluşmaktadır. 


\subsection{Veri Toplama Araçları (Data Collection Tools)}

Veri toplama aracı olarak, araştırmacılar tarafından bir gözlem formu hazırlanarak, alanında uzman kişiler tarafından incelenmesi sağlanmıştır. Sınıf eğitimi alan uzmanlarının tavsiyeleri ve uyarıları da dikkate alınarak gözlem formuna son şekli verilerek araştırma alanına uygulanması sağlanmıştır. Araştırmacılar tarafından geliştirilmiş olan bu gözlem formuna göre öğrencilerin sahip olduğu çeşitli değişkenler araştırılmış ve bulunma/bulunmama, sahip olduğu fiziksel özelliklerin durumuna göre gözlem formuna kaydedilmiştir.

Tablo 1. Araştırmacılar tarafından geliştirilmiş olan gözlem formu (Table 1 . Observation form developed by researchers)

\begin{tabular}{|c|c|}
\hline Öğrencinin C & Cinsiyeti \\
\hline Öğrencinin Y & Yaşı \\
\hline öğrencinin 0 & Okula Gelirken Kullandığı Ulaşım Türü \\
\hline Öğrencinin $\mathrm{K}$ & Kayıtlı Olduğu Okul Türü \\
\hline Öğrencinin 0 & Okuduğu Sınıf Düzeyi \\
\hline Öğrencinin S & Sahip Olduğu Çanta Şekli \\
\hline Öğrencinin B & Boyu \\
\hline Öğrencinin $\mathrm{K}$ & Kilosu \\
\hline Öğrencinin T & Taşıdığı Çanta Ağırlı̆̆ı \\
\hline Öğrencinin Ç & Çantasında Taşıdığı Kitap Sayısı \\
\hline Öğrencinin Ç & Çantasında Taşıdı ğı Defter Sayısı \\
\hline Öğrencinin B & Beslenme Çantasına Sahip Olma Durumu \\
\hline Öğrencinin S & Suluğa Sahip Olma Durumu \\
\hline Öğrencinin K & Kalemliğe Sahip Olma Durumu \\
\hline Öğrencinin R & Resim Çantasına Sahip Olma D \\
\hline
\end{tabular}

\subsection{Verilerin Toplanması (Collection of Data)}

İlkokullarda öğrenim gören öğrencilerin fiziksel özellikleri ile çanta içerik ve ağırlıklarının mevcut durumunu belirlemeyi amaçlayan bu araştırmaya ilişkin veriler, araştırmacılar tarafından bizatihi uygulama ve gözlem yapılarak elde edilmiştir.

\subsection{Verilerin Analizi (Data Analysis)}

Araştırma konusunun genel çerçevesine ilişkin literatür taraması yapılıp, uzman görüşleri de alınarak bir gözlem formu hazırlanmıştır. Araştırmada elde edilen verileri çözümlemede SPSS paket programından olup, yüzde, frekans ve aritmetik ortalama teknikleri kullanılarak değerlendirilmiştir. Sadece betimsel analizler yapıldığı belirtilmekle beraber, bulgular kısmında çıkarımsal istatistikler de yer almaktadır.

\section{BULGULAR (FINDINGS)}

Bu bölümde, araştırma sonuçlarına ilişkin elde edilen bulgular tablolar halinde sunulmuş ve değerlendirilmiştir.

\subsection{Araştırmaya Katılanların Cinsiyet Durumlarına Göre Genel Dağılımı (General Distribution of the Participants by Gender Status)}

Araştırmaya katılmış olan katılımcıların cinsiyet değişkenine göre dağılımı aşağıda Tablo 1'de gösterilmektedir. Tablo 1 incelendiğinde; araştırmaya katılanların \%50.4'ünün erkek ve \%49.6'sının da kız öğrenciden oluştuğu görülmektedir. 
Tablo 1. Araştırmaya katılanların cinsiyet durumlarına göre dağılımı

(Table 1. Distribution of the participants according to their gender status)

\begin{tabular}{|l|c|c|}
\hline Cinsiyet & $f$ & 을 \\
\hline Erkek & 459 & 50.39 \\
\hline Kadın & 451 & 49.61 \\
\hline Toplam & 910 & 100 \\
\hline
\end{tabular}

\subsection{Araştırmaya Katılanların Yaşa Göre Genel Dağılımı (General Distribution of the Participants by Age)}

Araştırmaya katılan katılımcıların yaşa değişkenine göre genel dağılımı aşağıda Tablo 2'de gösterilmektedir. Tablo 2 incelendiğinde, araştırmaya katılanların \%2.6'sının 6 yaş, \%21.9'unun 7 yaş, \%26.8'inin 8 yaş, 25.6'nın 9 yaş, 21.6'nın 10 yaş, ⒈3'ünün 11 yaş ve \%0.1'inin 12 yaş oldukları görülmektedir.

Tablo 2. Araştırmaya katılanların yaşa göre genel dağılımı

(Table 2. General distribution of survey participants by age)

\begin{tabular}{|l|c|c|}
\hline Yaş & $F$ & $\frac{\circ}{0}$ \\
\hline 6 Yaş & 24 & 2.6 \\
\hline 7 Yaş & 199 & 21.9 \\
\hline 8 Yaş & 244 & 26.8 \\
\hline 9 Yaş & 233 & 25.6 \\
\hline 10 Yaş & 197 & 21.6 \\
\hline 11 Yaş & 12 & 1.3 \\
\hline 12 Yaş & 1 & 0.1 \\
\hline Toplam & 910 & 100 \\
\hline
\end{tabular}

\subsection{Araştırmaya Katılanların Ulaşıma Göre Genel Dağılımı (General Distribution of the Participants by Access)}

Araştırmaya katılan katılımcıların okula giderken kullanmış oldukları ulaşım durumuna göre genel dağılımı aşağıda Table 3'te gösterilmektedir. Tablo 3 incelendiğinde, araştırmaya katılanların ○15.3'ünün yürüyerek 43.0'ın anne-baba yürüyerek \%37.5'inin servis, \%4.3'ünün anne-baba özel aracı ile ulaşım sağlandığı görülmektedir.

Tablo 3. Araştırmaya katılanların ulaşıma göre genel dağılımı (Table 3. General distribution of the participants in the research by transportation)

\begin{tabular}{|l|c|c|}
\hline Ulaşım & $f$ & $\frac{\circ}{\circ}$ \\
\hline Yürüyerek & 139 & 15.3 \\
\hline Anne-Baba Yürüyerek & 391 & 43.0 \\
\hline Servis & 341 & 37.5 \\
\hline Anne-Baba Özel Aracı & 39 & 4.3 \\
\hline Toplam & 910 & 100 \\
\hline
\end{tabular}

\subsection{Araştırmaya Katılanların Okul Türüne Göre Genel Dağılımı (General Distribution of the Participants by School Type)}

Araştırmaya katılan katılımcıların okul türüne devamları durumuna göre genel dağılımı aşağıda Tablo 4'te gösterilmektedir.

Tablo 4. Araştırmaya katılanların okul türüne göre genel dağılımı (Table 4. General distribution of the participants in the research by school type)

\begin{tabular}{|l|c|c|}
\hline Okul Türü & $f$ & $\frac{\circ}{\circ}$ \\
\hline Merkez & 810 & 89.0 \\
\hline Belde-Köy & 50 & 5.5 \\
\hline Özel & 50 & 5.5 \\
\hline Toplam & 910 & 100 \\
\hline
\end{tabular}


Tablo 4 incelendiğinde, araştırmaya katılan okulların o89'ının merkez, ⒌5'nin belde-köy, ⒌5'nin özel olduğu görülmektedir.

\subsection{Araştırmaya Katılan Öğrencilerin Sınıf Düzeyine Göre Genel Dağılımı (General Distribution of the Students Participating in the Research by Grade Level)}

Araştırmaya katılan katılımcıların bulundukları sınıf düzeyine göre genel dağılımları aşağıda Tablo 5'te gösterilmektedir.

Tablo 5. Araştırmaya katılan öğrencilerin sınıf düzeyine göre genel dağılımı

(Table 5. General distribution of the students participating in the research by class level)

\begin{tabular}{|l|c|c|}
\hline Sınıf Düzeyleri & $\mathrm{f}$ & $\frac{\circ}{\circ}$ \\
\hline 1 & 215 & 23.6 \\
\hline 2 & 213 & 23.4 \\
\hline 3 & 288 & 31.6 \\
\hline 4 & 194 & 21.3 \\
\hline Toplam & 910 & 100 \\
\hline
\end{tabular}

Tablo 5 incelendiğinde, araştırmaya katılan öğrencilerin \%23.6'sı

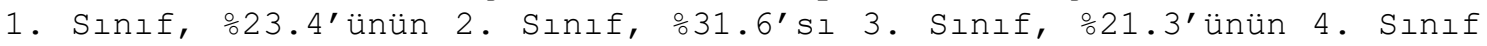
olduğu görülmektedir.

\subsection{Araştırmaya Katılanların Çanta Şekline Göre Genel Dağılımı (General Distribution of the Participants by Bag Shape)}

Araştırmaya katılan katılımcıların çanta şekline sahip olma durumuna göre genel dağılımı aşağıda Tablo 6'da gösterilmektedir.

Tablo 6. Araştırmaya katılanların çanta şekline göre genel dağılımı

(Table 6. General distribution of the participants according to the shape of the bag)

\begin{tabular}{|l|c|c|}
\hline Çanta Şekli & $f$ & $\frac{\circ}{\circ}$ \\
\hline Askılı & 858 & 94.3 \\
\hline Çekmeli & 50 & 5.5 \\
\hline Sadece tutmalı & 1 & 0.1 \\
\hline Çantasız & 1 & 0.1 \\
\hline Toplam & 910 & 100 \\
\hline
\end{tabular}

Tablo 6'ya bakıldığında; araştırmaya katılanların \%94.3'ünün askılı, ⒌5'inin çekmeli, 0.1'inin sadece tutmalı, 0.1'inin çantasız olduğu görülmektedir.

\subsection{Araştırmaya Katılanların Boy Durumuna Göre Genel Dağılımı (General Distribution of the Participants by Height)}

Araştırmaya katılan 910 ilkokul öğrencilerinin boy durumu mininmum $106 \mathrm{~cm}$ maksimum olarak da $152 \mathrm{~cm}$ aralığındadır. Öğrencilerin ortalama boy durumu $128.46 \mathrm{~cm}^{\prime} \mathrm{dir}$.

\subsection{Araştırmaya Katılanların Kilo Durumuna Göre Genel Dağılımı (General Distribution of the Participants by Weight Status)}

Araştırmaya katılan 910 ilkokul öğrencilerinin kilo durumu minimum $16 \mathrm{~kg}$ maksimum olarak da $65.60 \mathrm{~kg}$ aralığındadır. Öğrencilerin ortalama kilo durumu 28.48 kg'dır. 


\subsection{Araştırmaya Katılanların Çanta Ağırlığı Durumuna Göre Genel Dağllımı (General Distribution of the Participants by Bag Weight Status)}

Araştırmaya katılan 910 ilkokul öğrencilerinin çanta ağırlığı durumu minimum $1.00 \mathrm{~kg}$ maksimum olarak da $8.90 \mathrm{~kg}$ aralığındadır. öğrencilerin çantaların ortalama ă̆ırlığı 3.56 kg'dır.

\subsection{Araştırmaya Katılan Öğrencilerin Çantalarındaki Kitap Sayısı Durumuna Göre Genel Dağılım (Number of Books in the Bags of the Students Participating in the Research)}

Araştırmaya katılan katılımcıların çantalarında taşıdıkları kitap sayısı durumuna göre genel dağılımı aşağıda Tablo 7'de gösterilmektedir.

Tablo 7. Araştırmaya katılan öğrencilerin çantalarındaki kitap sayısı durumuna göre genel dağılım

(Table 7. General distribution according to the number of books in the bags of the students participating in the study)

\begin{tabular}{|l|c|c|}
\hline Kitap Sayısı & $f$ & $\frac{0}{0}$ \\
\hline 0 & 1 & 0.1 \\
\hline 1 & 7 & 0.8 \\
\hline 2 & 46 & 5.1 \\
\hline 3 & 139 & 15.3 \\
\hline 4 & 178 & 19.6 \\
\hline 5 & 161 & 17.7 \\
\hline 6 & 148 & 16.3 \\
\hline 7 & 103 & 11.3 \\
\hline 8 & 50 & 5.5 \\
\hline 9 & 30 & 3.3 \\
\hline 10 & 22 & 2.4 \\
\hline 11 & 9 & 1.0 \\
\hline 12 & 8 & 0.9 \\
\hline 13 & 4 & 0.4 \\
\hline 14 & 2 & 0.2 \\
\hline 16 & 1 & 0.1 \\
\hline 17 & 1 & 0.1 \\
\hline Toplam & 910 & 100 \\
\hline
\end{tabular}

Tablo 7 incelendiğinde; araştırmaya katılan öğrencilerin çantalarındaki kitap sayısı durumunda \%0.1'inin 0, \%0.8'inin 1 tane, \%5.1'inin 2 tane, ⒖3'ünün 3 tane, ⒚6'sının 4 tane, ะ17.7'sinin 5 tane, ⒗3'ünün 6 tane, ⒒3'ünün 7 tane, $\% 5.5^{\prime}$ inin 8 tane, $\% 3.3^{\prime}$ ünün 9 tane, $\frac{\circ}{2} .4^{\prime}$ ünün 10 tane, $\% 1.0^{\prime}$ In 11 tane, $\% 0.9^{\prime}$ un 12 tane, $\% 0.4^{\prime}$ ün 13

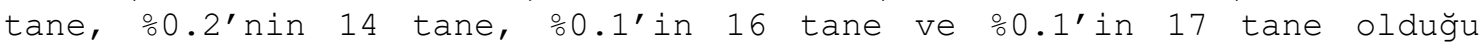
görülmektedir. Ayrıca araştırmaya katılan her bir öğrencinin çantasında ortalama 5.32 tane kitap vardır.

\subsection{Araştırmaya Katılan Öğrencilerin Çantalarındaki Defter} Sayısı Durumuna Göre Genel Dağılım (General Distribution by the Number of Notebooks in the Bags of the students Participating in the Study)

Araştırmaya katılan katılımcıların çantalarında taşıdıkıarı defter sayısı durumuna göre genel dağılım aşağıda Tablo 8'de gösterilmektedir. Tablo 8 incelendiğinde; araştırmaya katılan öğrencilerin çantalarındaki defter sayısı durumunda ⒉3'ünün 0, ⒎1'nin 1 tane, ⒓9' unun 2 tane, \%19.8'inin 3 tane, ⒗4'ünün 4 tane, ⒒6'sının 5 tane, \%11.6'sının 6 tane, ⒎5' unun 7 tane, ⒊8'inin 8 tane, ⒉7'sinin 9 tane, \%1.9'unun 10 tane, \%0.9'unun 11 tane, \%1.0' ın 12 tane ve \%0.4'ünün 13 tane olduğu görülmüştür. Ayrıca araştırmaya katılan her bir öğrencinin çantasında ortalama 4.39 tane defter vardır. 
Tablo 8. Araştırmaya katılan öğrencilerin çantalarındaki defter sayısı durumuna göre genel dağılım

(Table 8. General distribution according to the number of notebooks in the bags of the students participating in the study)

\begin{tabular}{|l|c|c|}
\hline Defter Sayıs & f & \% \\
\hline 0 & 21 & 2.3 \\
\hline 1 & 65 & 7.1 \\
\hline 2 & 117 & 12.9 \\
\hline 3 & 180 & 19.8 \\
\hline 4 & 149 & 16.4 \\
\hline 5 & 106 & 11.6 \\
\hline 6 & 106 & 11.6 \\
\hline 7 & 68 & 7.5 \\
\hline 8 & 35 & 3.8 \\
\hline 9 & 25 & 2.7 \\
\hline 10 & 17 & 1.9 \\
\hline 11 & 8 & 0.9 \\
\hline 12 & 9 & 1.0 \\
\hline 13 & 4 & 0.4 \\
\hline Toplam & 910 & 100 \\
\hline
\end{tabular}

4.12. Araştırmaya Katılan Öğrencilerin Beslenme Çantası Durumuna Göre Genel Dağılım (General Distribution According to the Lunch Box Status of the Students Participating in the Study)

Araştırmaya katılan katılımcıların beslenme çantasına sahip olma durumuna göre genel dağılım aşağıda Tablo 9'da gösterilmektedir.

Tablo 9. Araştırmaya katılan öğrencilerin beslenme çantası durumuna göre genel dağılım

(Table 9. General distribution according to the status of the lunchbox of the students participating in the study)

\begin{tabular}{|l|c|c|}
\hline Beslenme Çantasına Sahip Olma Durumu & $f$ & $\frac{\circ}{\circ}$ \\
\hline Var & 578 & 63.5 \\
\hline Yok & 332 & 36.5 \\
\hline Toplam & 910 & 100 \\
\hline
\end{tabular}

Tablo 9 incelendiğinde; araştırmaya katılan öğrencilerin beslenme çantası durumunda 63.5'inin var, 36.5'inin yok olduğu görülmektedir.

\subsection{Araştırmaya Katılan Öğrencilerin Suluk Durumuna Göre Genel Dağılım (General Distribution by Drinking Status of the Students Participating in the Study)}

Araştırmaya katılan katılımcıların suluğa sahip olma durumuna göre genel dağılım aşağıda Tablo 10'da gösterilmektedir.

Tablo 10. Araştırmaya katılan öğrencilerin suluk durumuna göre genel dağılım

(Table 10. General Distribution by Drinking Status of the Students Participating in the Study)

\begin{tabular}{|l|c|c|}
\hline Suluk Sahibi Olma Durumu & $\mathrm{f}$ & $\frac{\circ}{\circ}$ \\
\hline Var & 799 & 87.8 \\
\hline Yok & 111 & 12.2 \\
\hline Toplam & 910 & 100 \\
\hline
\end{tabular}

Tablo 10 incelendiğinde; araştırmaya katılan öğrencilerin suluk durumunda \%87.8'inin var, ⒓2' sinin yok olduğu görülmektedir. 
4.14. Araştırmaya Katılan Öğrencilerin Kalemlik Durumuna Göre Genel Dağılım (General Distribution According to the Pencil Status of the Students Participating in the Research)

Araştırmaya katılan katılımcıların kalemliğe sahip olma durumuna göre genel dağılım aşağıda Tablo 11'de gösterilmektedir.

Tablo 11. Araştırmaya katılan öğrencilerin kalemlik durumuna göre genel dağılım

(Table 11. General distribution according to the pencil case of the students participating in the research)

\begin{tabular}{|l|c|c|}
\hline Kalemliğe Sahip Olma Durumu & $\mathrm{f}$ & $\frac{\circ}{\circ}$ \\
\hline Var & 903 & 99.2 \\
\hline Yok & 7 & 0.8 \\
\hline Toplam & 910 & 100 \\
\hline
\end{tabular}

Tablo 11 incelendiğinde; araştırmaya katılan öğrencilerin kalemlik durumunda \%99.2'sinin var, 0.8'inin yok olduğu görülmektedir.

\subsection{Araştırmaya Katılan Öğrencilerin Resim Çantası Durumuna Göre Genel Dağılım (General Distribution of the Students Participating in the Study According to the Status of the Picture Bag)}

Araştırmaya katılan katılımcıların resim çantasına sahip olma durumuna göre genel dağılım aşağıda Tablo 12'de gösterilmektedir.

Tablo 12. Araştırmaya katılan öğrencilerin resim çantası durumuna göre genel dağılım

(Table 12. General distribution of the students participating in the study according to their picture bag)

\begin{tabular}{|l|c|c|}
\hline Resim Çantasına Sahip Olma Durumu & $\mathrm{f}$ & $\%$ \\
\hline Var & 22 & 2.4 \\
\hline Yok & 888 & 97.6 \\
\hline Toplam & 910 & 100 \\
\hline
\end{tabular}

Tablo 12 incelendiğinde; araştırmaya katılan öğrencilerin resim çantası durumunda \%2.4'ünün var, 97.6'sının yok olduğu görülmektedir.

4.16. Araştırmaya Katılanların Cinsiyet Değişkenine Göre Çanta Ağırlıklarının Karşılaştırılması (Comparison of Bag Weights According to the Gender Variable of the Participants)

Araştırmaya katılan katılımcıların cinsiyet değişkenine göre çanta ağırlıklarının karşılaştırılması aşağıda Tablo 13'te gösterilmektedir.

Tablo 13. Araştırmaya katılanların cinsiyet değişkenine göre çanta ă̆ırlıklarının karşılaştırılması

(Table 13. Comparison of bag weights according to the gender variable of the participants)

\begin{tabular}{|l|c|c|c|c|c|c|c|c|}
\hline & \multicolumn{3}{|c|}{ Erkek } & \multicolumn{3}{|c|}{ Kadın } & \multirow{2}{*}{ t } & \multirow{2}{*}{$\mathrm{p}$} \\
\cline { 1 - 7 } Nitelik & $\mathrm{n}$ & $\overline{\mathrm{X}}$ & $\mathrm{ss}$ & $\mathrm{n}$ & $\overline{\mathrm{X}}$ & $\mathrm{ss}$ & & 0.89 \\
\hline Çanta Agırlık & 458 & 3.55 & 1.21 & 451 & 3.56 & 1.15 & 0.13 & 0.89 \\
\hline
\end{tabular}

$\star \mathrm{P}<.05$

Araştırmaya katılanların cinsiyet değişkenine göre çanta ağırlıklarının karşılaştırıldığı Tablo 13 incelendiğinde, yapılan t testi sonucunda *p<.05 düzeyinde anlamlı fark olmadığı görülmektedir. Dolayısıyla ilkokul öğrencilerinin cinsiyet değişkenine göre çanta ağırlıkları arasında anlamlı bir fark yoktur. 


\subsection{Araştırmaya Katılanların Öğrenim Gördüğü Okul Türü Değişkenine Göre Çanta Ağırlıklarının Karşılaştırılması (Comparison of Bag Weights According to the Variable of School Type of Study Participants)}

Araştırmaya katılan katılımcıların öğrenim gördüğü okul türü değişkenine göre çanta ağırlıklarının karşılaştırılması aşă̆ıda Tablo $14^{\prime}$ te gösterilmektedir.

Tablo 14. Araştırmaya katılanların öğrenim gördüğü okul türü değişkenine göre çanta ağırlıklarının karşılaştırılması

[Table 14. Comparison of bag weights according to the variable of the school type of the study participants]

\begin{tabular}{|c|c|c|c|c|c|c|c|c|c|}
\hline \multirow[t]{2}{*}{ Nitelik } & \multicolumn{2}{|c|}{$\begin{array}{c}\text { Merkez } \\
\text { Okul (a) }\end{array}$} & \multicolumn{2}{|c|}{ Köy Okul (b) } & \multicolumn{2}{|c|}{ Özel Okul (d) } & \multicolumn{2}{|c|}{ Varyans } & \multirow{2}{*}{$\begin{array}{c}\text { Fark } \\
\text { Olan } \\
\text { Gruplar }\end{array}$} \\
\hline & $\mathrm{x}$ & $\mathrm{S}$ & $\overline{\mathrm{X}}$ & $S$ & $\overline{\mathrm{X}}$ & $S$ & $\mathrm{~F}$ & $\mathrm{p}$ & \\
\hline $\begin{array}{c}\text { Çanta } \\
\text { Ağırlık }\end{array}$ & 3.56 & 1.15 & 4.32 & 1.27 & 2.83 & 1.08 & 20.58 & $\star 0.0$ & $\begin{array}{c}a-b, a- \\
c, b-c\end{array}$ \\
\hline
\end{tabular}

$\star \mathrm{P}<.05$

Araştırmaya katılanların öğrenim gördüğü okul türü değişkenine göre çanta ağırlıklarına yönelik karşılaştırma Tablo 14' da verilmiştir. Yapılan tek yönlü varyans analizi sonucunda, çanta ağırlıklarında *p<.05 düzeyinde anlamlı farkın olduğu görülmektedir. Tablo 14 incelendiğinde araştırmaya katılanların öğrenim gördüğü okul türü değişkenine göre çanta ağırlıklarına yönelik karşılaştırmada yapılan varyans analizi sonucunda anlamlı farklılığın olduğu görülmektedir [f=20.58; *p<.05]. Merkez okullarda öğrenim gören öğrencilerin çanta ağırlığı ( $\bar{X}=3.56)$ köy okulunda öğrenim gören öğrencilerin çanta ağırlığından ( $\bar{X}=4.32)$ daha az olduğu yapılan lsd testi sonucunda görülmektedir. Özel okullarda öğrenim gören öğrencilerin çanta ağırlığı ( $\bar{X}=2.83)$ köy okulunda öğrenim gören öğrencilerin çanta ağırlığından ( $\bar{X}=4.32)$ daha az olduğu görülmektedir. Yine özel okullarda öğrenim gören öğrencilerin çanta ağırlığı ( $\bar{X}=2.83)$ merkez okullarda öğrenim gören öğrencilerin çanta ağırlığından $(\bar{X}=3.56)$ daha az olduğu yapılan lsd testi sonucunda görülmektedir. Genel sonuç olarak çanta ağırlığı en fazla olan öğrenci grubu köy okulunda; en az olan öğrenci grubu ise özel okulda öğrenim gören öğrenciler olduğu görülmektedir. Bu sonuç, özel okulda öğrenim gören öğrencilerin sınıflarında her öğrenciye ait bir dolabın bulunması ve ödevleri daha çok son ders saatinde sınıfla beraber öğretmen nezaretinde yapmasından dolayı öğrencilerin ders kitaplarını daha az eve götürmelerinden kaynaklandığı şeklinde yorumlanabilir. Ayrıca köy okulunda öğrenim gören öğrencilerin sınıflarında her öğrenciye ait bir dolabın bulunmamasından dolayı öğrencilerin ders kitaplarını daha fazla eve götürmelerinden kaynaklandığı söylenebilir.

\subsection{Araştırmaya Katılanların Öğrenim Gördüğü Sınıf Değişkenine Göre Çanta Ağırlıklarının Karşılaştırılması (Comparison of Bag Weights According to the Variable of the Class of Study Participants)}

Araştırmaya katılan katılımcıların öğrenim gördüğü sınıf değişkenine göre çanta ağırlıklarının karşılaştırılması aşağıda tablo 15'te gösterilmektedir.

Araştırmaya katılanların öğrenim gördüğü sınıf değişkenine göre çanta ağırlıklarına yönelik karşılaştırma Tablo 15'te verilmiştir. Yapılan tek yönlü varyans analizi sonucunda, çanta ağırlıklarında *p<.05 düzeyinde anlamlı farkın olduğu görülmektedir. 
Zengin, E. ve Turan, M., Education Sciences (NWSAES), 1C0701, 2020; 15(4):85-98.

Tablo 15. Araştırmaya katılanların öğrenim gördüğü sınıf değişkenine göre çanta ağırlıklarının karşılaştırılması

(Table 15. Comparison of the weight of the bags according to the variable of the class of the study participants)

\begin{tabular}{|c|c|c|c|c|c|c|c|c|c|}
\hline \multirow{2}{*}{ Nitelik } & \multicolumn{2}{|c|}{ Merkez Okul(a) } & \multicolumn{2}{c|}{ Köy Okul (b) } & \multicolumn{2}{c|}{ Özel Okul(d) } & \multicolumn{2}{|c|}{ Varyans } & $\begin{array}{c}\text { Fark } \\
\text { Olan } \\
\text { Gruplar }\end{array}$ \\
\hline $\begin{array}{c}\text { Çanta } \\
\text { Ağlrlık }\end{array}$ & 3.56 & 1.15 & 4.32 & 1.27 & 2.83 & 1.08 & 20.58 & $* 0.0$ & $\begin{array}{c}\mathrm{a}-\mathrm{b}, \mathrm{a}- \\
\mathrm{C}, \mathrm{b}-\mathrm{c}\end{array}$ \\
\hline
\end{tabular}

Tablo 15 incelendiğinde araştırmaya katılanların öğrenim gördüğü sınıf değişkenine göre çanta ağırlıklarına yönelik karşılaştırmada yapılan varyans analizi sonucunda anlamlı farklılığın olduğu görülmektedir $(f=40.594 ; \quad * p<.05)$. Birinci sınıfta öğrenim gören öğrencilerin çanta ağırlığı ( $\bar{X}=3.07)$; ikinci sınıf $(\bar{X}=3.57)$, üçüncü sınıf $(\bar{X}=3.44)$ ve dördüncü sınıfta öğrenim gören öğrencilerin çanta ağırlığından ( $\bar{X}=4.26)$ daha az olduğu yapılan lsd testi sonucunda görülmektedir. İkinci sınıfta öğrenim gören öğrencilerin çanta ă̆ırlığı $(\bar{X}=3.57)$, dördüncü sınıfta öğrenim gören öğrencilerin çanta ağırlığından $(\bar{X}=4.26)$ daha az olduğu yapılan lsd testi sonucunda görülmektedir görülmektedir. Ayrıca üçüncü sınıfta öğrenim gören öğrencilerin çanta ağırlığı ( $\bar{X}=3.44)$, dördüncü sınıfta öğrenim gören öğrencilerin çanta ağırlığından $(\bar{X}=4.26)$ daha az olduğu yapılan lsd testi sonucunda görülmektedir. Genel sonuç olarak; çanta ağırlığı en fazla olan sınıf grubu dördüncü sınıf; en az olan sınıf grubu ise birinci sınıfta öğrenim gören öğrenciler olduğu görülmektedir. Bu sonuç, dördüncü sınıfta öğrenim gören öğrencilerin öğrenim gördükleri ders sayısının fazla olmasından kaynaklandığı şeklinde yorumlanabilir. Ayrıca birinci sınıfta öğrenim gören öğrencilerin öğrenim gördükleri ders sayısının az olması ve daha çok derslerde Türkçe ve matematik dersinin ağırlıkıı yürütülmesinden kaynaklandığı söylenebilir.

\section{SONUÇ, TARTIŞMA VE ÖNERİLER (CONCLUSION, DISCUSSION AND SUGGESTIONS)}

Yapılan araştırma sonunda ilkokul öğrencilerinin; 58.3'ünün yürüyerek ve bu öğrencilerin o94.3'ünün çanta taşıyarak okula gittikleri tespit edilmiştir. Çanta taşıyarak ve yürüyerek okula giden öğrencilerin \%70.4'ünün 4-8 tane kitap, \%59.4'ünün çantasında 4-6 tane defter, \%99.2'sinin çanta ile birlikte kalemlik, o87.8'inin çanta ile birlikte suluk ve $\% 36,5^{\prime}$ inin ise çanta ile birlikte beslenme çantası taşıyarak okula gittikleri tespit edilmiştir. Çanta ile birlikte taşınan kitap, defter, kalemlik, beslenme çantası ve suluk gibi eşyaların da fazla olması, bu eşyaların öğrenim süreci içerisinde öğrencinin ihtiyaç duyduğu malzemeler olmasının ve ekonomik olarak ucuz olmalarından kaynaklandığı söylenilebilir. İlköğretim öğretmenlerinin görüşüne göre derslerde araç gereç kullanmak hem öğretmen açısından hem de öğrenciler açısından oldukça yararlı sonuçlar doğurmaktadır. Öğretmenlerin araç gereçlere yönelik tutumlarının olumlu olduğu görülmektedir ve öğretmenler araç gereç kullanımının önemini bilmektedirler. Fakat sosyoekonomik durumu iyi olan öğrencilerin okula getirmesi gereken araç-gereç ile sosyo-ekonomik durumu düşük olan öğrencilerin okula getirdikleri araç-gereçler arasında fark olduğu ve öğretmenler bu konuda problem yaşadıkları tespit edilmiştir. Ekonomik olarak durumu iyi olan öğrencilerin ekonomik durumu düşük olan öğrencilerden daha fazla araçgereç getirdikleri, ayrıca ekonomik olarak durumu düşük olan öğrencilerin eğitim-öğretim için temel teşkil eden malzemeleri getirdikleri sonucuna varılmıştır [9]. 


\begin{abstract}
Araştırmaya katılan 910 ilkokul öğrencilerinin çanta ağırlığı durumu minimum $1.00 \mathrm{~kg}$ maksimum olarak da $8.90 \mathrm{~kg}$ aralığındadır. Öğrencilerin çantaların ortalama ağırlığı 3.56 kg'dır. Araştırmaya katılan 910 ilkokul öğrencilerinin kilo durumu minimum 16 kg maksimum olarak da $65.60 \mathrm{~kg}$ aralığındadır. Öğrencilerin ortalama kilo durumu 28.48 kg'dır. Yapıla çalışmalar çocuğun çantasındaki malzeme ağırıı̆̆ının kendi kilosunun o10'dan fazla olmaması gerektiği vurgulanmıştır [12, 16 ve 31]. Araştırmaya göre öğrencilerin kilo ortalamalarının 10 2.84 olduğu görülmektedir. Öğrencilerin taşıdıkları ağırlık ortalaması 2.84 olması gerekirken, taşınan çanta ağırlık ortalaması 3.56 olduğu tespit edilmiştir. Çanta ağırlık ortalamasının öğrencilerin sahip olduğu kilo ortalamasından fazla olması çocuğun vücudunda ciddi sıkıntılara sebebiyet verebileceği düşünülmektedir. Ayrıca alanyazında yapılan araştırmalar çanta ağırlığının çocukta fiziksel sorunlara yol açabileceği gibi psikolojisinin de üstünde ciddi bir etkiye sahip olduğu tespiti yapılmıştır.
\end{abstract}

Hollanda'da iki Bölgesel Sağlık Merkezi bölgesinde 745 genç ergen üzerinde yürütülen kesitsel bir çalışma neticesinde; boyun ve omuz şikayetleri ve aynı zamanda sırt şikayetleri genç ergenlerin yaklaşık o45'i tarafından bildirilmiştir. Boyun ve omuzun şiddetli şikayetleri \%6, şiddetıi sırt ağrısı şikayetleri ise o7 oranındadır. Okul çantasının [nispi] ağırlığı, boyun ve sırt şikayetleriyle sınırlı değildi. Psikolojik sorunlar, okul çantasının tipi ve ağırlığına ve diğer fiziksel faktörlere göre boyun ve/veya omuz ve sırt şikayetleri ile güçlü bir şekilde ilişkili olduğu görülmüştür $[4,16,21$ ve 31]. Psikolojik sorunlar ile çanta ağırlığı arasındaki ilişkinin düzeyi gelecekte yapılacak olan araştırmalarda daha fazla irdelenebilir. Araştırma sonucunda; çanta ağırıı̆̆ı en fazla olan öğrenci grubu köy okulunda; en az olan öğrenci grubu ise özel okulda öğrenim gören öğrenciler olduğu görülmektedir. Bu sonuç, özel okulda öğrenim gören öğrencilerin sınıflarında her öğrenciye ait bir dolabın bulunması ve ödevleri daha çok son ders saatinde sınıfla beraber öğretmen nezaretinde yapmasından dolayı öğrencilerin ders kitaplarını daha az eve götürmelerinden kaynaklandığı şeklinde yorumlanabilir. Ayrıca köy okulunda öğrenim gören öğrencilerin sınıflarında her öğrenciye ait bir dolabın bulunmamasından dolayı öğrencilerin ders kitaplarını daha fazla eve götürmelerinden kaynaklandığı söylenebilir.

Ayrıca; çanta ağırlığı en fazla olan sınıf grubu dördüncü sınıf; en az olan sınıf grubu ise birinci sınıfta öğrenim gören öğrenciler olduğu görülmektedir. Bu sonuç, dördüncü sınıfta öğrenim gören öğrencilerin öğrenim gördükleri ders sayısının fazla olmasından kaynaklandığı şeklinde yorumlanabilir. Ayrıca birinci sınıfta öğrenim gören öğrencilerin öğrenim gördükleri ders sayısının az olması ve daha çok derslerde Türkçe ve matematik dersinin ağırlıklı yürütülmesinden kaynaklandığı söylenebilir. Çocukların çanta kullanma alışkanlıkları doğru olmasına rağmen, özellikle sırtta ağrı hissetmelerinin nedeninin, asimetriden ve çanta ağırlığından kaynaklandığı düşünülmektedir. İlkokul çocuklarında asimetrinin bir kısmı normal ve büyüme döneminde düzelecek olarak kabul edilse bile, bir kısım bozuklukların erken dönemde fark edilmesi ve erişkin dönemde çocuğun günlük yaşantısını etkilememesi açısından, okul taramasının yapılması ve ailenin bilgilendirilmesi gerekmektedir [4]. Bununla birlikte, sırt çantası kullanımı ile ve yük faktörleri, sırt çantası tasarımı ve fiziksel uygunluk gibi kişisel özelliklerin bir sırt çantasını taşırken gerekli uyarlamaları nasıl etkilediğini ve bu etkiyi belirlemek için daha fazla araştırma yapılması gerekmektedir [2] . 


\section{KAYNAKLAR (REFERENCES)}

[1] Al-Khabbaz, Y.S.S.M., Sihimada, T., and Hasegawa, M., (2008). The Effect of Backpack Heaviness on Trunk-lower Extremity Muscle Activities and Trunk Posture, Gait \& Posture, 28(2):297-302. DOI : http://dx.doi.org/10.1016/j.gaitpost.2008.01.002.

[2] Brackley, H.M. and Stevenson, J.M., (2004). Are Children's Backpack Weight Limits Enough?: A Critical Review of the Relevant Literature. Spine, 29 (19):2184-2190.

[3] Connolly, B.H. diğerleri.., (2008). Effects of Backpack Carriage on Gait Parameters in Children, Pediatric Physical Therapy, $20(4), 347-355$ DOI: 10.1097/PEP.0b013e31818a0f8f

[4] Demir, Y.P., Çırak, Y., Dalkılınç, M., Yılmaz, G.D., Uraş, İ. ve Kömürcü, M., (2012). İlkokul Çocuklarında Çanta Taşıma, Bilgisayar Kullanma Alışkanlığı ve Postür. Ankara Medical Journal, $12(4)$.

[5] Dockrella, S., (2017). Schoolbeg Carriage and Schoolbeg-Related Musculoskeletal Pain in Primary School Children in Ireland, A Report for the Joint Committee on Children and Youth Affairs. 16 .

[6] Dockrella, S., Simmsb, C., and Blakec, C., (2015).Schoolbag Carriage And Schoolbag-Related Musculoskeletal Discomfort Among Primary School Children. Elsevier Ltd and The Ergonomics Society, 51, 281-290.

[7] Daneshmandi, H., Rahmani-Nia, F., and Hosseini, S.H., (2008). Effect of Carrying School Backpacks on Cardio-Respiratory Changes in Adolescent Students. Sport Sci Health, 4, 7-14. DOI 10.1007/s11332-008-0060-8.

[8] Dockrella, S., Kanea, C., and O'Keeffe, E., (2006). Schoolbag Weight and the Effects of Schoolbag Carriage on Secondary School Students. School of Physiotherapy, Trinity Centre for Health Sciences, Trinity College Dublin, http://www.iea.cC/ECEE/pdfs/art0212.pdf, (Er.Tarihi: 15.10 .2017 ).

[9] Fidan, N.K., (2008). İlköğretimde Araç Gereç Kullanımına İlişkin Öğretmen Görüşleri. Kuramsal Eğitimbilim Dergisi, 1(1):48-61.

[10] Geraldine, I., Sheir-Neiss, P.D., Richard, W., Kruse, D.O., Tariq Rahman, P.D., Lisa, P., Jacobson, S.D., Jennifer, A., and Pelli, M.S., (2003). Association of Backpack Use and Back Pain in Adolescents, Spine. $28(9)$.

[11] Gündüz, H. ve Özarslan, N., (2016). Farklı Yaş Kategorilerinde İlkokula Başlayan Öğrencilerin Okul Olgunluğu ve Öğretmen Görüşlerine Göre Okula Uyum Problemleri. Abant İzzet Baysal Üniversitesi Eğitim Fakültesi Dergisi, 17(1):212-230.

[12] Hong, Y. and Brueggemann, G.P., (2000). Changes in Gait Patterns in 10-Year-old Boys with Increasing Loads When Walking on A Treadmill. Gait \& posture, $11(3): 254-259$.

[13] Janakiraman, B., (2014). School Bags and Musculoskeletal Pain Among Elementary School Children In Chennai City, International Journal of Medical Science and Clinical Invention, 6:302-309 ISSN: $2348-991 X$.

[14] Kabilmiharbi, N. and Santhirasegaram, T., (2017). A Study on Relationship Between Carrying Schoolbags and The Prevalence of Neck and Back Pain Among 7-9 Year Old Students, MATEC Web of Conferences 87, 02013. DOI: 10.1051/ matecconf/20178702013.

[15] Kistnet, F., Fiebert, I., and Roach, K., (2012). Effect of Backpack Load Carriage on Cervical Posture in Primary Schoolchildren. Work, $41(1): 99-108$. 
[16] Lai, J.P.H. and Jones, A.Y.M., (2001). The Effect Of ShoulderGirdle Loading by A School Bag on Lung Volumes in Chinese Primary School Children. Early human development, 62 (1):79-86.

[17] MEGEP, (2009). Çocuk Gelişimi ve Eğitimi Çocuğun Gelişimi, http://megep.meb.gov.tr/mte_program modul/moduller_pdf/Geli。C5\%9 Fim.pdf, (Erişim Tarihi: 10.10.2017).

[18] Milli Eğitim İstatistikleri Örgün Eğitim 2012-2013. Milli Eğitim Bakanlığı Resmi İstatistik Programı Yayını. 2013. Ankara. ISBN 978-975-11-3744-9.

[19] Moore, M.J., White, G.L., and Moore, D.L., (2007). Association of Relative Backpack Weight with Reported Pain, Pain Sites, Medical Utilization, and Lost School Time in Children and Adolescent. J Sch Health. $77(5): 232-9$.

[20] Mosaad, D. and Abdel-aziem, A.A., (2015). Backpack Carriage Effect on Head Posture and Ground Reaction Forces in School Children. Work, 52(1):203-9. DOI: 10.3233/WOR-152043.

[21] Negrini, S. and Carabalona, R., (2002). Backpacks on! Schoolchildren's Perceptions of Load, Associations with Back Pain and Factors Determining The Load. Spine, 27 (2):187-195.

[22] Pau, M., Mandaresu, S., Leban, B., and Nussbaum, M.A., (2014). Short-Term Effects of Backpack Carriage on Plantar Pressure and Gait in Schoolchildren. Journal of Electromyography and Kinesiology, $25(2): 406-412$.

[23] Pau, M., Corona, F., Leban, B., and Priolo, E., (2010). Postural Sway and Foot-Ground Relationship are Significantly Modified by Backpack Carriage during Upright Stance: A Study on Primary School Children, Innovation in Aging, 1. DOI : $10.1093 /$ geroni/igx004.1307.

[24] Paua, M. and Paub, M., (2010). Postural Sway Modifications Induced by Backpack Carriage in Primary School Children: A Case Study in Italy. Ergonomics. $53(7)$ :872-88.

[25] Paula, A.J.F., Silva, J.C.P., and Silva, J.C.R.P., (2015). The Influence of Load Imposed by the Backpack School in Children and Teens in Brazil. Procedia Manufacturing (Elsevier), 3:5350-5357.

[26] Ramprasad, M. and Alias, J., (2010). Raghuveer AK. Effect of Backpack Weight on Postural Angles in Preadolescent Children. Indian Pediatr, $47(7): 575-80$.

[27] Saleem, A., diğerleri., (2016). A Study of School Bag Weight and Back Pain among Primary School Children in Al-Ahsa, Saudi Arabia, Epidemiology (Sunnyvale). February; 6(1):222. DOI : 10.4172/2161-1165.1000222.

[28] Sato, T., Ito, T., Hirano, T., Morita, O., Kikuchi, R., Endo, N., and Tanabe, N., (2011). Low Back Pain in Childhood and Adolescence: Assessment of Sports Activities. Eur Spine J. $20: 94-99$.

[29] Shasmin, H.N., Osman, N.A., Razali, R., Usman, J., and Abas, W.A.B., (2007). A Preliminary Study of Acceptable Load Carriage for Primary School Children, IFMBE Proceedings (15):171-174.

[30] Taimela, S., Kujala, U., Salminen, J.J., and Viljanen, T., (1997). The Prevalence of Low Back Pain Among Children and Adolescents. A nationwide, cohort-based questionnaire survey in Finland. Spine. 22:1132-1136.

[31] van Gent, C., Dols, J.J., Carolien, M., Sing, R.A.H., and De Vet, H.C., (2003). The Weight of Schoolbags and the Occurrence of Neck, Shoulder, and Back Pain in Young Adolescents. Spine, 28 (9) : $916-921$.

[32] Yavuz, C., (2019). Does Internet Addiction Predict Happiness for The Students of Sports High School?. International Online Journal of Educational Sciences, $11(1)$. 